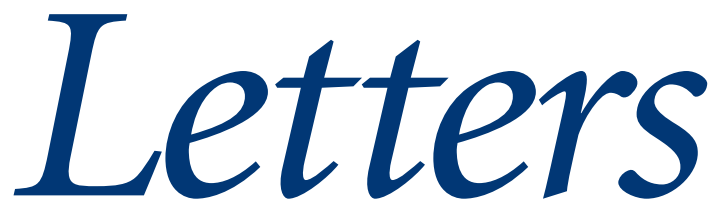

All letters are subject to editing and may be shortened. Letters should be sent to the BJGP office by e-mail in the first instance, addressed to journal@rcgp.org.uk (please include your postal address). Alternatively, they may be sent by post as an MS Word or plain text version on CD or DVD. We regret that we cannot notify authors regarding publication. Letters not published in the Journal may be posted online on our Discussion Forum. For instructions please visit: http://www.rcgp.org.uk/bjgp-discuss

\section{Sick children}

James Cave provides a good comment on the articles about management of acutely ill children. ${ }^{1}$

It seems barely credible that British GPs fail to use basic, simple tests such as pulse, respiration, capillary return, and temperature in assessing acutely ill children. Perhaps they see so few really ill children in a year that they can get away with it.

I wonder what they do in the 15 or 20 minute consultations after making the general observation that the child is either well or ill!

A 1960s film was titled The Knack ... and How to Get It. I believe it referred to chat up lines by young men. If being a careful family doctor is just to do with a acquiring the knack for safe diagnosis all well and good, but without a systematic approach, 'general impression' is bound to fail some children.

In my practice I do not have the luxury of a paediatrician at a referral centre or an ambulance service to rescue the cases that I miss. Here in rural Gambia our locally-trained (school grade 9) nurses are taught the four observations (as stated above and by Cave) which should be used with any ill child, supplemented by a simplified coma score (Blantyre coma score). Results are reproducible from observer to observer and an urgent request for the doctor to see the sick child is the result. I tend to repeat the same observations to confirm the severity of the case, en route to a diagnosis and treatment.

The proviso is that WHO Integrated Management of Childhood Illness guidelines suggest actually counting respiratory rate for a full, timed minute.
Perhaps a minute is too long for highly trained doctors to sit still and count, but I would suggest that this can be a quiet interlude in which to allow parents and the child to watch you take a careful, objective view. Following that, most doctors can listen to the family while counting the (usually regular) pulse.

Brandishing a stethoscope is not likely to help any further and anyway stops the clinician from hearing the family while his/her ears are blocked!

Poor overall appearance of the child is also important, but parents with their own children are just as likely to tell you this without the benefit of any medical training, particularly for a child who you have not seen recently.

As a junior anaesthetist I learned that risks drop to rarities when you do things systematically. GPs could do well to take the same line.

\section{James Erskine}

Sibanor Rural Health Centre, PO Box 86 Banjul, The Gambia. E-mail: erskinesjd@yahoo.co.uk

\section{REFERENCE}

1. Cave J. Managing the acutely ill child. Br J Gen Pract 2008; 58(549): 228-229.

DOI: 10.3399/bjgp08X302718

\section{Alcohol policies}

An essay in the April issue of the $B J G P^{1}$ spells out clearly the need for a truly 'strategic', multilevel policy response to the growing problem of alcohol-related illness in the UK. Even in core primary care services, like maternity care or family planning, patterns of alcohol use across the lifespan cause multi-faceted problems. ${ }^{2}$ Within schools' revised personal, social, and health education programme, alcohol education is a prominent area, but we are struggling now to create good learning materials and to build confidence among teachers that they can help 'make being drunk socially unacceptable'.'

My own accumulating observations in community settings, around domestic violence, or children entering local authority care, just drove me to join the new special interest group for Alcohol and Violence (launched by the UK Public Health Association). At the political level, we need to "resist corporate pressure"1 not just from the alcohol industry but from a wider leisure and tourism sector that has a powerful hold over the present government. At a professional level, too, we ought to acknowledge that most NHS provision for alcohol dependence is ineffective, and that alcoholics stay away in droves! ${ }^{3}$

In the course of re-thinking our alcohol services, it may be useful to look at more effective partnerships between health professionals and the voluntary sector, as this appears to be synergistic in helping patients with alcohol, family, and employment problems. ${ }^{4}$ Across England, local authorities and primary care trusts are now working out specific priorities for 'local area agreements', within which healthy communities are a national priority. GPs are uniquely placed to introduce credible and creative ideas around alcohol into these local agreements.

\section{Woody Caan}

Professor of Public Health, Department of Child and Family Health, East Road, Cambridge, CB1 1PT.

E-mail: a.w.caan@anglia.ac.uk

\section{REFERENCES}

1. Mirza ZA, Lakasing E. Government strategy on alcohol. Time to revise legislation and implement wider interventions. Br J Gen Pract 2008; 58(549): 286-287. 
2. Caan W. Remember the links in the causal chain of fetal alcohol effects. Lancet 2007; 369(9575): 1789.

3. Luty J. Specialised alcohol treatment services are a luxury the NHS cannot afford. Br J Psychiatry 2008; 192: 245-247.

4. Baldacchino A, Caan W, Munn-Giddings C. Mutual aid groups in psychiatry and substance misuse. Ment Health Subst Use 2008; 1: 104-117.

DOI: 10.3399/bjgp08X302727

\section{Plain English}

Andrew Bolton, a very successful fund manager, advises that whenever you plan to buy a stock, try to explain the reason for your choice in a few simple sentences that your teenage children can understand.

I have recently applied this stratagem to the 'conclusion' section of BJGP original article summaries. Complete confusion ensues; the sentences are long and obfuscatory and the point/benefit of the research baffling to my children and myself.

Please try to use simple clearer English. If a research team cannot really explain simply what they are trying to do and why, ask for a revised draft. Does the College now have a in-house style that few ordinary jobbing GPs can understand?

NB enjoyed the Pickles Lecture ${ }^{1}$ and the 'proper doctor' vignette. ${ }^{2}$

\section{Roderick Champ}

Urishay Barn, Michaelchurch Escley,

Hereford, HR2 OLR.

E-mail: quinnchamp@gmail.com

\section{REFERENCES}

1. Hilton S. Education and the changing face of medical professionalism: from priest to mountain guide? Br J Gen Pract 2008; 58(550): 353-361.

2. Lester H. On being a proper doctor. Br J Gen Pract 2008; 58(550): 378 .

DOI: 10.3399/bjgp08X302736

\section{Re: Plain English}

A familiar (and fair) point. The bit that we think should be easy to grasp is the
'How this fits in' section - that at least is the intention. The instruction to write it so an intelligent child can understand it is so useful we'll add it - Ed.

DOI: 10.3399/bjgp08X302745

\section{HIV testing}

We wholeheartedly agree with the letter from Barber et al ${ }^{1}$ regarding the need for a lower threshold of HIV testing outside of traditional GU medicine settings.

Clinicians in general practice should not be afraid of offering HIV tests where clinically indicated or if requested by the patient. Let's reiterate the advice that 'counselling' is not required (although you must gain consent from the patient before testing) and that life insurance issues should not be a deterrent to offering an HIV test. If the HIV result returns as negative, insurance companies do not need to be informed; in fact, with improved treatments resulting in a better prognosis, some insurance companies are now happy to offer cover to some HIV-positive patients.

What are the clinical indications for HIV testing? Not only the signs and symptoms that would raise suspicion of HIV infection, but also the opportunistic offer of an HIV test to those patients from certain high-risk groups, such as:

- people from sub-Saharan Africa (and their sexual partners);

- men who have sex with other men (and their sexual partners);

- injecting drug users (and their sexual partners); and

- commercial sex workers and their clients.

What signs and symptoms might prompt suspicions of HIV infection?

- tuberculosis (the British HIV Association recommends all patients with TB, regardless of their perceived risk of HIV infection, should be offered an HIV test ${ }^{2}$ );
- non-Hodgkin's lymphoma;

- recurrent skin infections (shingles, tinea, folliculitis); and

- severe or recalcitrant seborrhoeic dermatitis.

This list is not exhaustive and further, more comprehensive advice on HIV in primary care is available in an easy-toread booklet produced by the Medical Foundation for AIDS and Sexual Health (MedFASH) and available to download for free from their website. ${ }^{3}$

Guidance on managing other sexually transmitted infections in primary care has been produced by the Royal College of General Practitioners (RCGP) with the involvement of the British Association for Sexual Health and HIV $(\mathrm{BASHH})^{4}$, and is also available to download for free from the RCGP and BASHH websites.

The RCGP, supported by the Department of Health in partnership with BASHH, the Faculty of Sexual Health and Reproductive Healthcare, the Royal College of Nursing, and other relevant stakeholders, is also producing an Introductory Certificate in Sexual Health aimed at increasing awareness of HIV and sexual health matters in general practice. Using a similar format to the highly successful RCGP Certificate in the Management of Drug Misuse Part 1, it will consist of an e-module and a face-to-face training day. This course is specifically aimed at generalists in general practice and addresses sexual health care including taking sexual histories, contraceptive issues, and management of STIs including HIV. (Further details can be obtained by emailing Russell Fleet at MedFASH. Contact details can be found at www.medfash.org.uk/)

Rates of HIV continue to rise in the UK. General practice clinicians are ideally placed to be vigilant with regard to HIV testing and this was highlighted last year by a letter from the Chief Medical and Nursing Officers encouraging HIV testing in all healthcare settings outside of those traditionally offering the service. ${ }^{5}$ Ample guidance is being made available to assist clinicians 